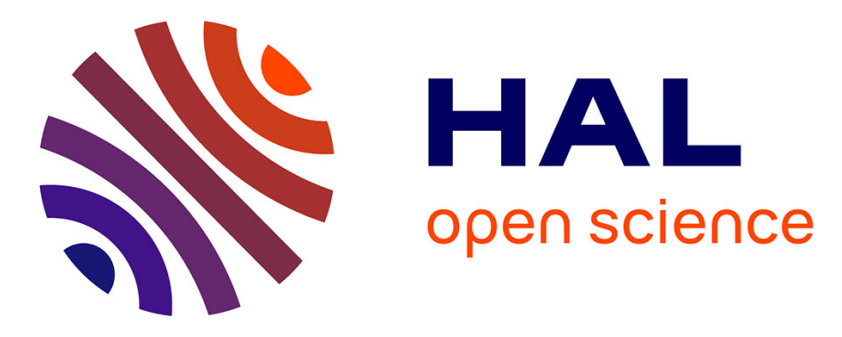

\title{
Taner filter settings and automatic correlation optimisation for cyclostratigraphic studies
}

Christian Zeeden, Stefanie Kaboth, Frederik J Hilgen, Jacques Laskar

\section{To cite this version:}

Christian Zeeden, Stefanie Kaboth, Frederik J Hilgen, Jacques Laskar. Taner filter settings and automatic correlation optimisation for cyclostratigraphic studies. Computers \& Geosciences, 2018, 119 (Octobre 2018), pp.18-28. 10.1016/j.cageo.2018.06.005 . hal-01958822

\section{HAL Id: hal-01958822 \\ https: / hal.sorbonne-universite.fr/hal-01958822}

Submitted on 18 Dec 2018

HAL is a multi-disciplinary open access archive for the deposit and dissemination of scientific research documents, whether they are published or not. The documents may come from teaching and research institutions in France or abroad, or from public or private research centers.
L'archive ouverte pluridisciplinaire HAL, est destinée au dépôt et à la diffusion de documents scientifiques de niveau recherche, publiés ou non, émanant des établissements d'enseignement et de recherche français ou étrangers, des laboratoires publics ou privés. 
1 Taner filter settings and automatic correlation optimisation for cyclostratigraphic

2 studies

3 Christian Zeeden ${ }^{{ }^{*}}$, Stefanie Kaboth ${ }^{2}$, Frederik J. Hilgen ${ }^{3}$, Jacques Laskar ${ }^{1}$

$4{ }^{1}$ IMCCE, Observatoire de Paris, PSL Research University, CNRS, Sorbonne Universités,

5 UPMC Univ. Paris 06, Univ. Lille, 75014 Paris, France;

$6{ }^{2}$ Heidelberg University, Department of Earth Sciences, Im Neuenheimerfeld 234, 69120

7 Heidelberg, Germany

$8{ }^{3}$ Department of Earth Sciences, Faculty of Geosciences, Utrecht University, Heidelberglaan

92 2, 3584CS, Utrecht, The Netherlands

$10{ }^{*}$ corresponding author: christian.zeeden@obspm.fr, phone: +33 140512038

Abstract

Cyclostratigraphy and astronomical tuning utilize the imprint of quasi-cyclic insolation changes in geological records to establish chronologies. In this context, filtering of time series in specific frequency bands is commonly applied to extract information on astronomical forcing from geological datasets. This approach is performed on specific insolation components (precession, obliquity or eccentricity) and sometimes also their amplitudes either in depth or time domain. In this study, we design and apply a simulation technique to determine the optimal Taner filter settings to extract precession-, obliquity- and eccentricity-related interference signals from astronomically tuned geological datasets. This is done by testing a variety of filter settings on several astronomical and artificial datasets. Based on our results, we propose specific filter designs (cut-off frequencies and roll-off rates) for the best extraction of astronomical (interference) signals from tuned geological datasets. Focus here lies on datasets shorter than ca. 1 million years and interference patterns between astronomical components.

A second step utilizes these filter settings for an automated alignment, where geological data on a tuned time scale are matched to a suite of astrochronologic correlation targets. This is done by aligning filter minima and maxima to astronomical targets. This approach is particularly useful for the determination of the relative contributions of astronomical parameters in a specific dataset and allows for the automatic determination of phase shifts between well expressed insolation components in datasets.

\section{Key words}

cyclostratigraphy; automated tuning; automated time scale optimisation; Taner filter settings; correlation

Competing interests statement:

No author has a competing interest

\section{Author contributions ${ }^{\star}$}


${ }^{*} \mathrm{CZ}$ carried out the programming and designed the study. SK helped applying methods to several test datasets, discussed these, and ensured suitable implementation. $\mathrm{FH}$ and $\mathrm{JL}$ oversaw the study and discussed the implementation and documentation. All authors contributed to the manuscript creation by writing, discussing changes for clarity and technical usefulness and correctness.

\section{Introduction}

Cyclostratigraphy relates quasi-cyclic patterns in sediments to astronomical characteristics which in turn are used for time scale reconstructions (e.g. Hinnov, 2000; Hinnov and Hilgen, 2012; Hilgen et al., 2015). These are then further aided by other dating techniques (i.e. Ar/Ar and $\mathrm{U} / \mathrm{Pb}$ dating). Generally, the quasi-cyclic patterns are extracted from geological datasets by filtering the data in the depth or time domain (e.g. Valero et al., 2014, 2016; Martinez and Dera, 2015; Da Silva et al., 2016). During the Neogene, direct astronomical tuning is often possible at the scale of precession ( $20 \mathrm{kyr}$; e.g. Shackleton and Crowhurst, 1997; Lourens et al., 2001; Abels et al., 2009; Zeeden et al., 2014). In particular, precession filtering of geological data and the extraction of their respective amplitudes have been used to reconstruct the astronomical imprint within geological datasets (e.g. Ding et al., 2002; Lourens et al., 2010). These filtered data patterns and amplitudes are also applied to test tuned time scales (Shackleton et al., Meyers, 2015; 1995; Zeeden et al., 2015). Yet, filter settings are commonly chosen quite arbitrarily, and we are aware of only one study which systematically investigates the effect of filter settings (Li et al., 2018).

Hence, we focus on filtering individual precession- obliquity and eccentricity cycles in a most representative way. We highlight that the filter settings suggested in this study are unsuitable for extracting amplitude variations of cycles, as for such investigations the full span of astronomical forcing must be included (see e.g. Hinnov, 2000), and wider filters must be applied (Zeeden et al., 2015).

Here, we focus on two different aspects related to cyclostratigraphy and time scale reconstructions: (1) Taner filters and (2) automated alignment of filter extremes to correlation targets. We focus on Taner filters (Taner, 1992) as they (a) are available in the 'astrochron' $R$ package (a widely used method in cyclostratigraphy; Meyers, 2014; R Core Team, 2017) and in matlab (http://mason.gmu.edu/ /hinnov/cyclostratigraphytools.html), and allow for automated application to various datasets, (b) their filter properties such as high and low filter cut-off frequencies and the roll-off rate, a parameter for the steepness of the filter boundaries, can easily be adjusted, and (c) they enjoy increasing popularity in the cyclostratigraphic community, (e.g. Wu et al., 2013; Boulila et al., 2014, 2015; Meyers, 2015; Laurin et al., 2016; Martinez et al., 2017). An intuitive visualisation of the Taner filter and its properties is given in Kodama (2015; their Fig. 4.5.). Comparing filters of geological data and astronomical targets, and especially their amplitudes, can give a direct (visual) impression of similarity.

Automated correlation is often regarded as a helpful tool and several methods have been proposed and published (Olea, 1994; Lisiecki and Lisiecki, 2002; Pälike, 2002; Huybers and Aharonson, 2010; Lin et al., 2014; Kotov et al., 2016; Edwards et al., 2018), and used (e.g. Lisiecki and Raymo, 2005; Pälike et al., 2006b; Necula and Panaiotu, 2008; Lang and Wolff, 
2011; Liebrand et al., 2011). Generally, these methods aim at a high-resolution correlation based on an initial time scale. However, they do not enjoy great popularity within the geosciences community. This may be because no-easy-to-use open source application was made available for cyclostratigraphic and geochronologic applications until recently (Kotov et al., 2016), while also care must be taken to take additional constraints from integrated stratigraphy into account (Hilgen et al., 2014) to avoid errors in automated correlation. The fear of geoscientists to be replaced by algorithms may also contribute to limit the application of such methods.

We suggest that automatic correlation approaches become especially useful when their freedom in changing sedimentation rates is limited, and an initial (tuned) time scale is the basis for further improvements. Here we describe and provide algorithms that (a) create an ensemble of tuning targets based on variable contributions of the individual astronomical parameters as well as variable phase relationships between them (Laskar et al., 2004), and (b) automatically optimise a correlation between a geological record and a specific target or an ensemble of tuning targets by aligning filtered data extremes (i.e., minima and maxima) to those in the targets.

\section{Experimental design and computer code}

\subsection{Taner filter settings for cyclostratigraphy: concept}

To find the best Taner filter settings for astrochronologic applications, we test the frequency range and steepness of various Taner filter settings. This is done by using the precession, obliquity and eccentricity from the La2004 astronomical solution (Laskar et al., 2004). In addition, a set of signal- and time-distortions are imposed on the solution, and the extraction of astronomical signals is tested on these datasets (see Table 1 for an overview). The details of these tests are outlined below, and the used R code is available in the Supplementary Materials.

\subsection{Taner filter settings for cyclostratigraphy: implementation}

For this study we utilized the R software (R Core Team, 2017) environment and the Taner (Taner, 1992) filter incorporated within the 'astrochron' R package (Meyers, 2014), because of the free availability and user flexibility of astrochron, and its increasing application in the astrochronology community. The La2004 astronomical solution (Laskar et al. 2004) is used at a $1 \mathrm{kyr}$ resolution as basis for our experiments with artificial datasets. For these datasets, we used the last one million years of the solution and a mix of precession and obliquity/tilt signals mimicking northern and southern hemisphere climate variability. In this context $\mathrm{p}-0.5 \mathrm{t}$ represents standardized precession minus $0.5^{*}$ standardized tilt (Lourens et al., 1996), and $0.5 p-t$ and $p$-t represent similar signals with a higher contribution of obliquity. The $-(p-0.5 t)$ is used for testing precession and obliquity filter settings. For reconstructing eccentricity, a mix of $p+0.5 t+e$ was used. The use of a one million year-long test dataset does not imply that results are only valid for time scales of this length. We choose this length as a case study because (a) it provides enough cycles to give statistically useful results for precession, obliquity and the $100 \mathrm{kyr}$ eccentricity components, (b) longer datasets would use more computing time, and (c) over such a length the frequency of precession and obliquity can be considered unchanged. 
The experimental setup is designed to test filter settings where a clear expression of an astronomical imprint is present in data, and also in more complicated cases which may be regarded suitable for mimicking real data. For testing precession filter settings, initially we test the possibility to extract precession from a $-p+0.5 t$ (experiment $\# 1$ ) and a $p-0.5 t$ (experiment \#2) dataset using the last 1 million years. After performing these experiments for idealized astronomical signals, we included 50, 100 and 200\% AR1-noise to the $-p+0.5 t$ dataset (experiments \#3-5) and to the p-t dataset (experiments \#6-8), which has a lower precession contribution and represents a less ideal case for extracting precession information. To test filter settings in cases where age models are imperfect, we include noise in artificial datasets (as in experiments \#3-5). We also include uncertainty in the artificial stratigraphic (time) domain (experiments \#9-11) by replacing age with a gamma distribution with shape and scale parameters of five and one respectively. Gamma distributions are limited to positive values and can therefore model a growing stratigraphic column and have been previously used for this purpose (Martinez et al., 2016). Finally, experiments \#12-14 are similar to \#9-11 but are clipped at zero to ensure only positive values. This represents a specific case of nonlinear response to astronomical forcing. Table 1 summarizes the experiments for precession, a supplementary R script performs these tests. For the optimisation experiments the procedure may be described as follows:

(1) Maximize abs(correlation between (original signal, filtered signal)),

(2) Subject to \{lower filter boundary, upper filter boundary, filter roll-off rate\}.

Testing filter settings for obliquity and eccentricity is done in a similar way, with a given basis for the eccentricity filter reconstruction of $p+0.5 t+e$. The full code of all the conducted individual experiments is attached as supplementary $R$ scripts. Results for experiments with obliquity and eccentricity are available as Supplementary Tables 1 and 2.

\subsection{Automatic generation of correlation target ensembles for cyclostratigraphic studies}

Although a single correlation reference dataset is often applied and may represent a suitable target, it might not be appropriate as the exact mix of astronomical parameters in a geological dataset is usually unknown, and also may vary with time. Therefore, we suggest testing a geological dataset against an ensemble of astronomical correlation targets with changing contributions of two of the three astronomical parameters precession $(P)$, obliquity/tilt $(T)$ and eccentricity $(E)$. To facilitate this, three $R$ functions are implemented, which generate correlation targets of (a) eccentricity and tilt (b) precession and tilt and (c) eccentricity and precession. The amount of different combinations, and the maximal phase lag of the longer period component can be set.

In this study, we abstained from including an experiment where all three astronomical parameters are mixed since: (a) often only one or two of the astronomical parameters are dominating geological datasets and hence are used as tuning targets (Kuiper et al., 2008; Liebrand et al., 2011; Zeeden et al., 2013; Boulila et al., 2015; e.g. Kaboth et al., 2016), (b) the relative phase information can be more directly retrieved when limiting the investigation to only two parameters, and (c) often eccentricity is present in geological records as amplitude modulation of the precession signal. Where a mix of precession, obliquity and eccentricity may be useful as correlation target, a correlation target can be easily generated using the established 'etp' function of the 'astrochron' R package (Meyers, 2014; R Core Team, 2017) on the basis of the La2004 solution. Also the amplitude modulation of obliquity is not used here, as it has no direct influence on insolation. 


\subsection{Generation of correlation targets: implementation}

The functions 'createETtargets', 'createPTtargets' and 'createEPtargets.R' automatically create a specific amount ( $\mathbf{N}$; parameters to be set in the $R$ functions in bold) targets with changing contributions of two astronomical parameters from a starting time (TimeMin) to a maximum age (TimeMax) in kyr before present with a temporal spacing of Dt kyr. The influence of hemispheres can be set for the 'createPTtargtes. $R$ ' and 'createPEtargets. $R$ ' functions, and maximal phase shifts of the obliquity relative to precession and eccentricity can be set using the phaseShift parameter, which represents the maximal phase shift in kyr. For the function 'createPTtargets. $R$ ' also a nonlinear reaction to precession and eccentricity may be tested by including setting the nc (nonlinar combinations) parameter to $>1$. This is done by applying the exponential function $\exp \left(\right.$ precession $\left.{ }^{*}{ }^{*} \mathrm{nc}\right)$ where $\mathrm{nc}$ represents the number of nonlinear combinations of amplified precession and obliquity. The multiplication by 5 is somewhat arbitrary chosen; it gives a useful difference of output reference datasets. This nonlinear amplification of precession may be useful in cases where precession is nonlinearly amplified in geological records during eccentricity maxima.

\subsection{Adjustment of correlative age models}

Several methods of automatic alignment between signals have been suggested which are all based on the principle of fully automatic alignment of datasets in high resolution (e.g. Lisiecki and Lisiecki, 2002; Lin et al., 2014; Kotov et al., 2016). We propose a different implementation in this study and assign maxima and minima of filtered geological data to corresponding maxima and minima in correlation targets. This limits the temporal flexibility of the method presented here to less than an investigated (precession, obliquity, eccentricity) cycle prominently present in data and used for age model construction.

The presented method requires high-resolution geological proxy data that record astronomical-scale changes with high fidelity. A data resolution of 1-3 kyr is suggested here for precession related variations allowing for the identification of precession/obliquity interference patterns. This data resolution and a tuned time scale are required to lead to useful results. Where a delayed response of proxy data may be expected, as e.g. in proxies for ice volume and soil development in the Quaternary (e.g. Thompson and Goldstein, 2006; Marković et al., 2015), care must be taken to initially obtain and tune to a useful (precession) phase. This may not be possible in all cases, as adjusting the phase of both precession and obliquity is not anticipated directly with this method.

The here proposed method uses a geological dataset, one or a set of correlation targets, and the temporal resolution as input parameters. It filters the data and target, aligns maxima (and minima) of these filter results, and selects the target resulting in a best fit. Linear interpolation of the age/depth relationship is applied between tie points.

We test the presented approach by applying the automatic correlation optimisation to two Miocene marine datasets from the Mediterranean and equatorial Atlantic. Both dataset show precession-obliquity interference patterns and both records were used for establishing integrated time scales (Hüsing et al., 2009; Zeeden et al., 2013, 2014; Wotzlaw et al., 2014). The first dataset is from Monte dei Corvi, Italy. This section was investigated for its integrated stratigraphy using astrochronology, magnetostratigraphy and also radiometric dating (Hilgen et al., 2003; Hüsing et al., 2007, 2009, 2010; Wotzlaw et al., 2014; Zeeden et al., 2014). A dataset of lightness as obtained by calorimetric measurement directly on 
outcropping sediments has previously been used to estimate the phase between precession and obliquity (Zeeden et al., 2014). Here, we test the existing tuning results through the application of our correlation algorithm. The second example is a colour reflectance record from ODP Leg 154, Site 926 in the equatorial Atlantic (Curry et al., 1995; Shackleton and Crowhurst, 1997; Zeeden et al., 2013). The colour reflectance variability has been interpreted to represent input of terrestrial material from the Amazon into the equatorial Atlantic (Harris et al., 1997; Dobson et al., 2001), and ODP Leg 154 shows a rather clear imprint of astronomical climate forcing, which was used in numerous studies ( Shackleton and Crowhurst, 1997; Shackleton et al., 1999; Pälike et al., 2006a; Wilkens et al., 2017). Here we analysed the time interval from 8.6 to 9 million years ago of this dataset using the corOptMinMax function.

\subsection{Implementing the adjustment of correlative age models}

The function performing the correlation optimisation 'corOptMinMax. $R$ ' can be used to test if the alignment improves or deteriorates the correlation. By setting the parameter deselectTiePoints to "T" (vs. "F"), tie points decreasing correlation can be deselected automatically until a minimum of 2 tie points is left. The resolution parameter can be set to focus on precession ("p"), obliquity ("o"), eccentricity ("e") or combinations ("po" for a combination of precession and obliquity and "eo" for a combination of eccentricity and obliquity). The function corOptMinMax uses a geological dataset (Data) and a target (target) as basic input, as well as the temporal resolution as Dt parameter. The maximum temporal difference between the filtered data maxima and minima to the correlation target can be set by the maxDiff parameter; this parameter limits the flexibility of the algorithm. The corOptMinMax function returns resulting correlation coefficients (here the spearman rank correlation to allow for nonlinearity in the relationship between data and targets) of the original time scale, the correlations resulting from adjustments and resulting tie points. The corOptMinMax function produces a list containing (a) the original correlation between optimal target and data (b) a variable including the optimal correlation, its contribution of obliquity and precession, the tuning target contributions of precession and obliquity and the lag of a second astronomical component if applicable (c) the re-tuned data and (d) the used tie points for re/tuning data.

\section{Results}

\subsection{Filter settings and generation of correlation targets}

Table 1 summarizes the results from the experiments investigating different filter settings for precession and Supplementary Tables 1 and 2 contain the results for obliquity and eccentricity. Please note that these results are partly based on resampling procedures and noise generation from specified distributions. To make results reproducible we set a seed in the $\mathrm{R}$ code. For all experiments, we investigate whether the ideal filter properties represent real optima in the settings, or if these lie in a range of values giving similar results. Especially the dependency of correlation results on the cut-off frequencies is for several experiments rather arbitrary (especially for precession and obliquity filters), as exemplary shown in Supplementary Fig. 1. In such cases, we estimate the narrow end of filter settings resulting in the best correlation; these estimates based on the inspection of relationships between parameters and correlation are also displayed in Table 1 and Supplementary Tables 1 and 2. 
Experiments show that for precession, filters are optimally set at frequencies from 0.043 to 0.054 [1/kyr], using a roll-off rate of $10^{28}$. These consistently perform well in a set of experiments with artificial data (Table 1). This includes testing its robustness in non-ideal circumstances as: (a) changing amount of noise, (b) different contributions of precession and obliquity, and (c) non-constant sedimentation rate. For obliquity, we suggest setting upper and lower filter limits at 0.022 and 0.029 [1/kyr] and the roll-off rate at $10^{3}$. Eccentricity of the last 1 million years is best reconstructed by setting filter boundaries to 0.003 and 0.012 applying a roll-off rate of $10^{3}$.

The corresponding R scripts (see section 2.4 and Supplementary Materials) automatically generate ensembles of correlation targets and are tested for a best fit with geological data hereafter.

\subsection{Adjustment of correlative age models}

The optimisation of correlation between two geological datasets and a mix of precession and obliquity is applied to two marine example datasets (see sections $2.5,2.6$ ). Figures $2-5$ represent the automatically generated output from the application of the 'corOptMinMax.R' function with some visual adjustments. For both datasets, we apply filter properties including precession and obliquity by setting the resolution parameter to "po". In this way we obtain information on the optimal mix of precession and obliquity, the obliquity phase, and improve the correlation between geological data and astronomical target.

The grey scale colour dataset from Monte dei Corvi for the interval from 9.6 to 9.0 Ma (Fig. 2 ) is best resembled by a combination of $0.48^{*}$ precession and $0.52^{*}$ obliquity in this time interval, and thus a clearly higher obliquity contribution than previously used (inverted $\mathrm{p}-0.5 \mathrm{t}$ ) for correlation to astronomic targets when considering longer intervals (Hilgen et al., 2003; Hüsing et al., 2010; Zeeden et al., 2014). This shows the varying contribution of precession and obliquity in long term eccentricity maxima and minima, where the $\mathrm{p}-0.5 \mathrm{t}$ gives a good overall fit of the Monte dei Corvi Record. An obliquity offset of $1 \mathrm{kyr}$ results in the best correlation by increasing the correlation coefficient slightly from 0.64 to 0.66 . Next, we consider two time intervals with clearly different precession and obliquity contributions (Figs. 3-4), from 9.6-9.3 and 9.3-9.0 Ma. The interval from 9.3-9.0 Ma (Fig. 3) is dominated by precession $(74 \%)$ where obliquity $(36 \%)$ plays a subordinate role. The correlation increases slightly from 0.71 to 0.74 with changing obliquity phase, but this phase might not be very reliable as the obliquity contribution is relatively weak. The interval from 9.6-9.3 Ma (Fig. 4) is dominated by obliquity (66\%) while precession plays a lower role (34\%). Obliquity is leading the signal by $2 \mathrm{kyr}$, and again the correlation can be improved a bit, here from 0.66 to 0.70 .

Using filter properties including precession and obliquity on the dataset from Ceara Rise suggests that a mix of $44 \%$ precession and $56 \%$ obliquity provide the best correlation target (Fig. 5). An obliquity offset of $1 \mathrm{kyr}$ results in a correlation coefficient of 0.66 ( 0.57 based on the original chronology). Results support the original tuning in this case, but propose a higher contribution of obliquity. It needs to be noted that this is a statement for this specific time interval only, and the overall good fit between the Ceara Rise record and the originally used target (inverted $\mathrm{p}-0.5 \mathrm{t}$ ) is not questioned here. 
315 Here we suggest specific filter settings for the optimal reconstruction of astronomical

316 parameters from geological datasets. We propose to use cut-off frequencies of 0.043 and

$3170.054[1 / \mathrm{kyr}]$ for filtering precession related signals and 0.022 and $0.029[1 / \mathrm{kyr}]$ for obliquity.

318 For eccentricity, the filter results $(0.003$ and $0.012[1 / \mathrm{kyr}])$ describe the periodicities around

$319100 \mathrm{kyr}$ well. In case of lower and very low frequency eccentricity components (e.g. Boulila

320 et al., 2012; Martinez and Dera, 2015) wider band-pass or low-pass filters will be more appropriate than the ones proposed in this study. While rather low roll-off rates perform best for eccentricity and obliquity, precession is best reconstructed when using high roll-off rates are used. This may be explained by most of precession components being in the filter range, while some low-frequency components of obliquity and eccentricity will only partly be captured by lower roll-off rates or alternatively wider filters, which then will also incorporate more non-astronomical data variability.

The filter properties designed in this study are adapted to recent precession and obliquity frequencies and are therefore particularly well suited for the Quaternary and Neogene time periods. However, because obliquity and precession periods were shorter in the past (Berger et al., 1992; Hinnov, 2000; Laskar et al., 2004), different filter settings will be optimal for preNeogene time intervals. Corresponding filter properties for older times are listed in Table 2. To determine the best filter settings for time intervals, the supplementary scripts can be adjusted to test pre-Neogene time intervals still covered by the La2004 solution by changing the timing (code lines 18-22). This script then automatically generates the best filter settings for an individual time interval, based on the precession and obliquity frequencies from Laskar et al. (2004). Table 2 provides an estimation of corresponding frequencies according to the evolution of frequencies by Laskar et al. (2004).

\subsection{Using large ensembles of correlation targets}

The method described here allows a direct correlation between proxy data and a large ensemble of correlation targets of which the best fit can automatically be selected. Additionally, it can be directly combined with further data analysis in $\mathrm{R}$, as e.g. provided by the 'astrochron' package (Meyers, 2014; R Core Team, 2017). It requires an initial time scale, and the maximum deviation of tie points from this initial time scale can be set, hence deliberately reducing the change in timing and possibility for misinterpretations. It may be argued that setting maximal deviation from original tuning is prescribing results. We agree that this may represent an issue. However, we see the possibility to avoid automatically implemented misinterpretations and therefore provided the option to limit the time offset. Additionally, the functions provided allow for the testing of various phase relationships between astronomical parameters automatically. Beside the automated tuning-optimisation our proposed application also includes the possibilities of optimal parametrization of ice volume models. In addition, the ensembles of targets and corresponding tunings allow stochastic approaches to investigate the effect of interpretations based on age models.

\subsection{Correlation optimisation and exemplary application}

The results from our proposed automated alignment approach are less arbitrary than manual tuning and produce higher correlation coefficients in the examples shown, although the aim here is to reconstruct the relative contributions of precession and obliquity. The automatic alignment of minima and maxima of filtered data requires an initial tuning (on the time scale to be achieved by automatic alignment, e.g. precession, obliquity or eccentricity), a clear expression of the astronomical parameters used for alignment and a constant phase relationship of proxy data to astronomical forcing. This method requires more guidance than other automatic alignment methods based on dynamic time warping and dynamical programming (e.g. Lisiecki and Lisiecki, 2002; Lin et al., 2014; Kotov et al., 2016), and is not 
meant to create a fully unguided correlation. The presented approach is developed to optimise a tuning, and mainly find the best fitting correlation target in large ensembles of $10 \mathrm{~s}$ to 100 s of options, the relative contributions of astronomical parameters and the phase of obliquity in precession and obliquity driven records. To our knowledge the methods described and the appended $\mathrm{R}$ scripts are the only open available and free-to-use possibility to test a dataset against large ensembles of correlation targets.

The Italian based Miocene example gives convincing results and correlation is similar to previously published results (Zeeden et al., 2014). In addition, we obtain information on the relative contributions of precession and obliquity, and the obliquity phase. The obliquity phase offset of $1 \mathrm{kyr}$ is consistent with cross-spectral analysis of a tuning to the $\mathrm{p}-0.5^{\star} \mathrm{t}$ reference, which resulted in an obliquity phase offset of up to $1.5 \mathrm{kyr}$ (Zeeden et al., 2014).

The dataset from Miocene drill cores recovered during ODP Leg 154 in the equatorial Atlantic shows a correlation coefficient of 0.61 when optimising the correlation. Improved results are in this case achieved when filter properties include precession and obliquity (versus filter properties only comprising precession, not shown), therefore we regard these results most useful.

In both experiments with real geological data, better results are obtained when filter settings include both obliquity and precession. This is probably because the datasets used are influenced by Northern Hemisphere insolation (Shackleton and Crowhurst, 1997; Hilgen et al., 2003) which comprises both precession and obliquity. Importantly, we show that the tuning target previously used are not necessary optimal for all time intervals, and that fitting short intervals to more suitable targets leads to a better correlation and an in detail better and more reproducible age model. However, it is important to highlight that here we focus on short intervals of much longer datasets. We here do not question the originally used correlation targets, which indeed give a good overall fit with the datasets.

The relative contribution of obliquity and precession are not constant over time, but depend on both astronomical forcing with changing parameter amplitudes (Laskar et al., 2004) and climate feedback (e.g. Rutherford and D'Hondt, 2000; Lisiecki and Raymo, 2005; Meyers and Hinnov, 2010; Zeeden et al., 2013). This limits the applicability of our approach to long time series, because better fits of data and targets can be expected for shorter intervals with similar forcing and feedback. For example the Monte dei Corvi record (Hilgen et al., 2003; Hüsing et al., 2009), part of which is used here as example, shows a good fit with the p-0.5t astronomical target when the overall record is considered. However, shorter intervals especially in long term eccentricity minima show a higher obliquity influence, as may be expected.

The information on the relative influence of astronomical parameters and their phase, which is obtained here by fitting numerous targets with changing influence of parameters, can be regarded the main aim and outcome, whereas a small increase in correlation does not provide much additional information.

\section{Conclusions}

Here we propose specific Taner filter settings to extract astronomical scale variations from geological tuned time series. Our experiments suggest the following filter properties for Quaternary and Neogene studies: For precession, filter boundaries are optimally set at frequencies of 0.043 and 0.054 using a roll-off rate of $10^{28}$. These consistently perform well in a set of experiments with artificial data. For obliquity, we suggest setting upper and lower 
filter limits at 0.022 and 0.029 and the roll-off rate at $10^{3}$. The components around $100 \mathrm{kyr}$ of eccentricity are best reconstructed by setting filter boundaries to 0.003 and 0.012 and by applying a roll-off rate of $10^{3}$. At least for precession, lower roll-off rates ( $\left.\sim 10^{2}\right)$ perform better in practice because even tuned age models are usually imperfect and therefore require investigating a wider frequency band. For deep-time records, different cut-off frequencies are necessary due to the evolution of precession and obliquity frequency through Earth history (see Tab. 2).

416 These investigated filter settings are in turn applied in an automatic alignment of filtered 417 geologic data, which we provide as a correlation optimisation method for testing geological 418 datasets against sets of correlation targets. Two geological datasets of Miocene marine successions are directly compared with large ensembles of targets (425 reference datasets, respectively). This guided alignment is preventing high deviations from an original age models, and therefore may be preferred over fully automatic alignments with less guidance. This method leads to a better understanding of the contribution of different astronomical parameters to a geological dataset, and can estimate phase of obliquity at the same time. We provide all code as $\mathrm{R}$ functions and scripts for further use in the supplementary materials.

\section{Acknowledgements}

CZ is financed through an PSL post-doctoral fellowship. All datasets used in this study are available in the Pangaea database, computer code is available as supplementary information. Four reviewers are thanked for their helpful comments which helped to improve this study.

\section{Computer Code Availability}

All computer code described here is available as code in the R language in supplementary materials. It was designed by C. Zeeden, IMCCE, Observatoire de Paris, PSL Research University, CNRS, Sorbonne Universités, UPMC Univ. Paris 06, Univ. Lille, 75014 Paris, France. Phone: +33 14051 2038. The code requires a decent computer, and the $R$ software including the 'astrochron' package installed. 
Figures and Tables

Filter data (at precession "p", obliquity "o" or a mix of both "po")

\section{$\downarrow$}

Find filter minima and maxima which are temporal close to those in target

$$
\downarrow
$$

Align minima and maxima in record to target

$$
\begin{array}{|c|}
\hline \begin{array}{c}
\text { Try to improve correlation } \\
\text { by least square fit }
\end{array} \\
\hline \downarrow
\end{array}
$$

Calculate correlation (until optimal value is reached)

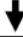

Output of data and plot

442 Figure 1: Flow chart of the automatic alignment method. Please note that filtering can also

443 be done in the frequency band of eccentricity and obliquity-eccentricity (see paragraph 2.2). 

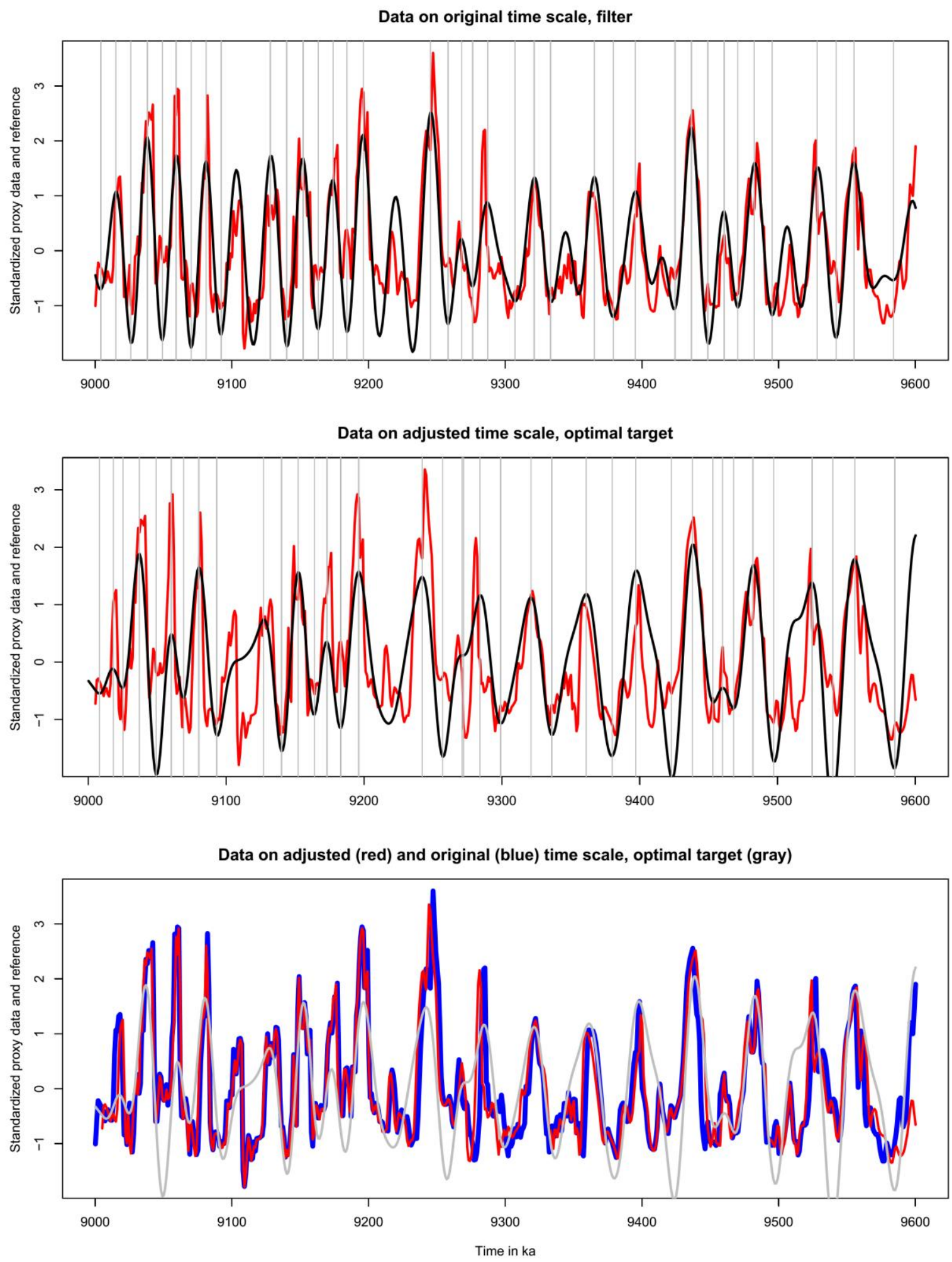

Figure 2: Grey scale colour data form Monte dei Corvi (Zeeden et al., 2014) on the original age scale (top), the adjusted age scale (using a filter comprising both precession and obliquity; middle panel), as well as a comparison of data on original and adjusted time scales (bottom panel) including the target fitting data best (grey). Vertical lines represent tie points between filtered data and the best-fitting correlation target. (for printing: black and white) 

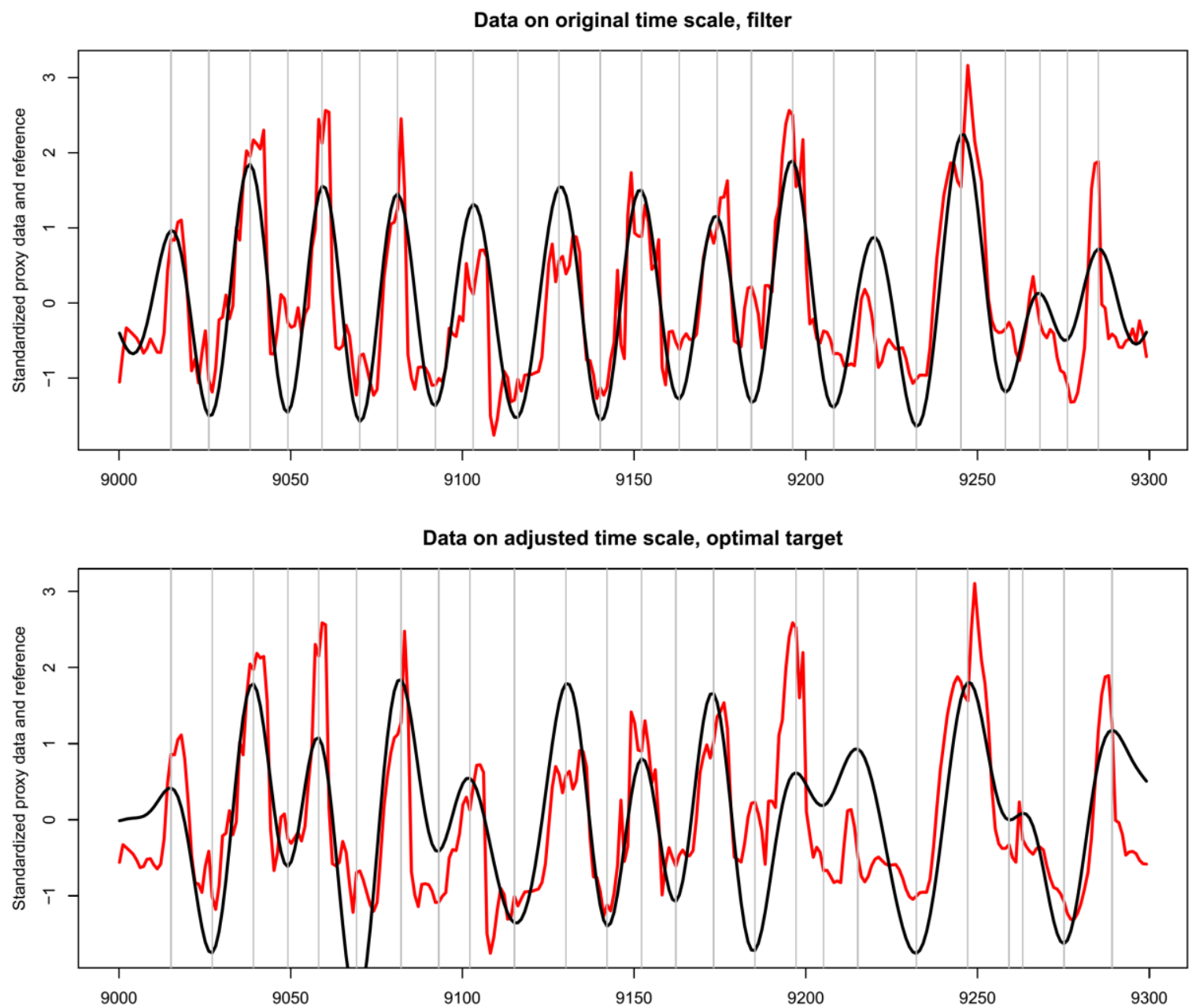

Data on adjusted (red) and original (blue) time scale, optimal target (gray)

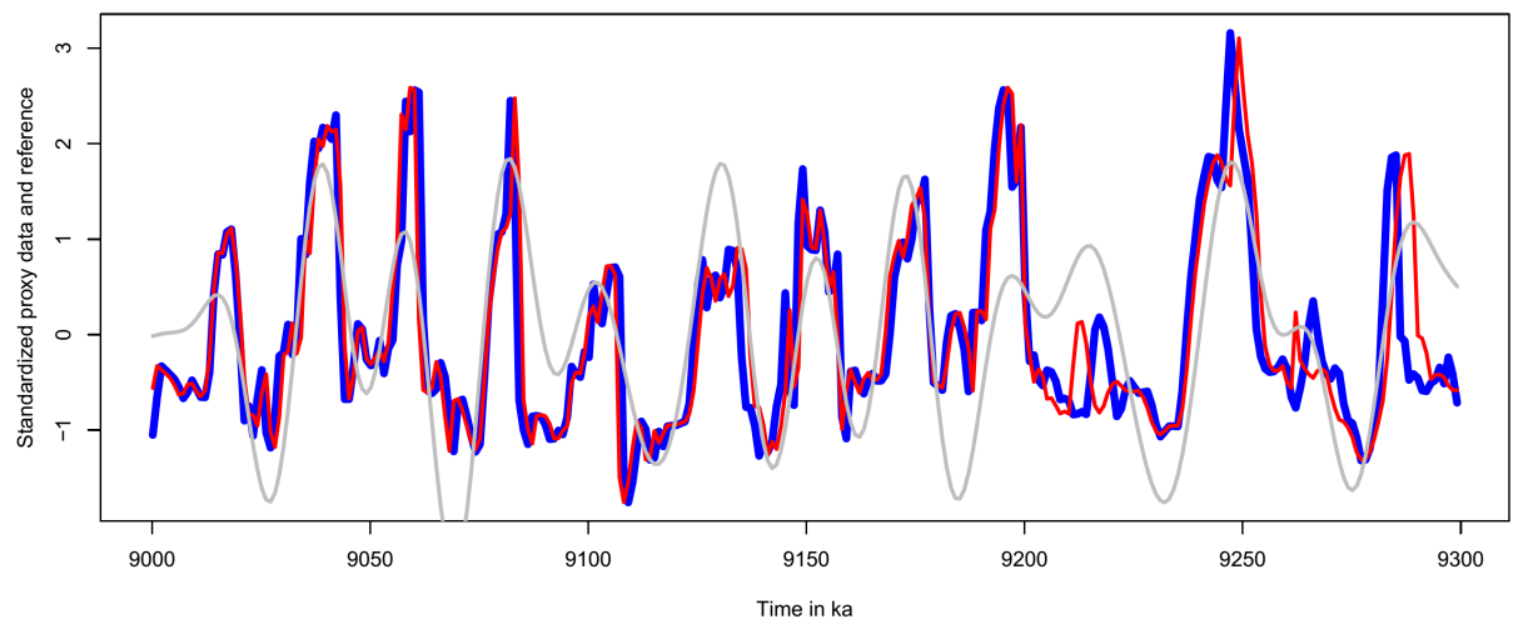

Figure 3: Younger and precession dominated part of figure 2. Grey scale colour data form Monte dei Corvi (Zeeden et al., 2014) on the original age scale (top), the adjusted age scale (using a filter comprising both precession and obliquity; middle panel), as well as a comparison of data on original and adjusted time scales (bottom panel) including the target fitting data best (grey). Vertical lines represent tie points between filtered data and the bestfitting correlation target. (for printing: black and white) 


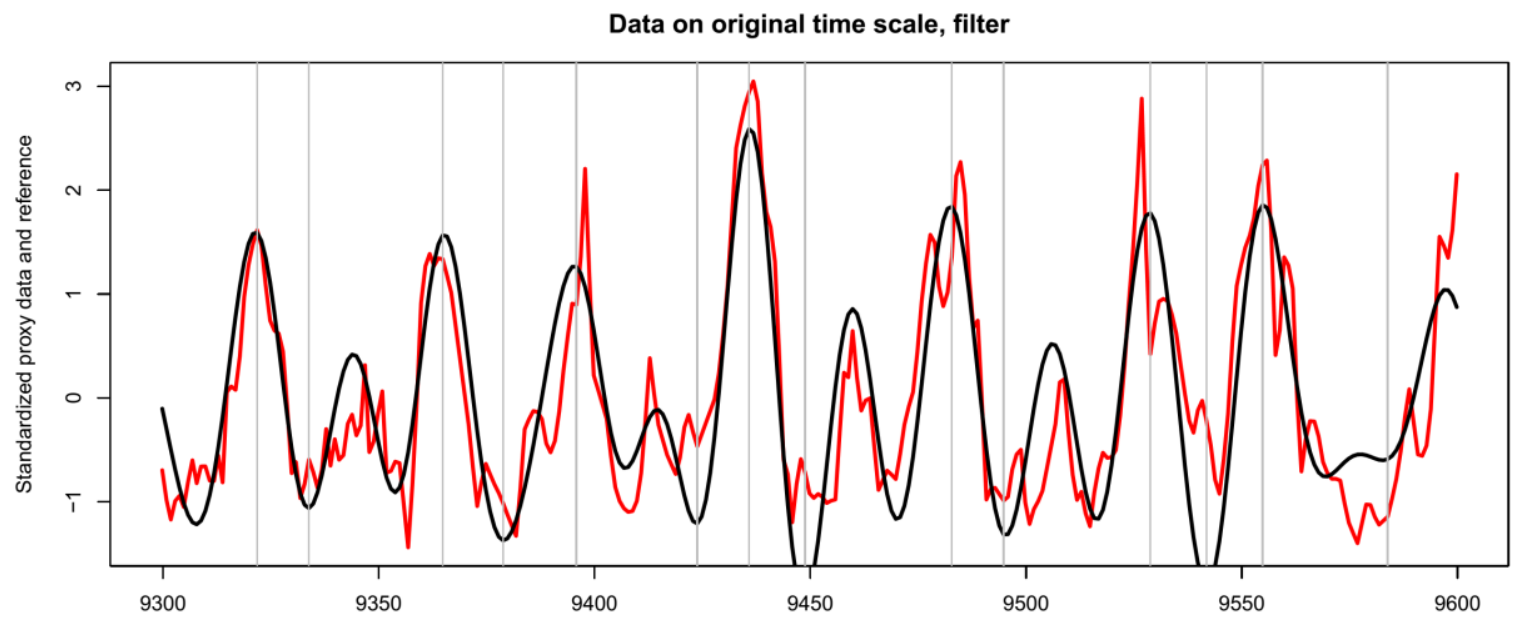

Data on adjusted time scale, optimal target

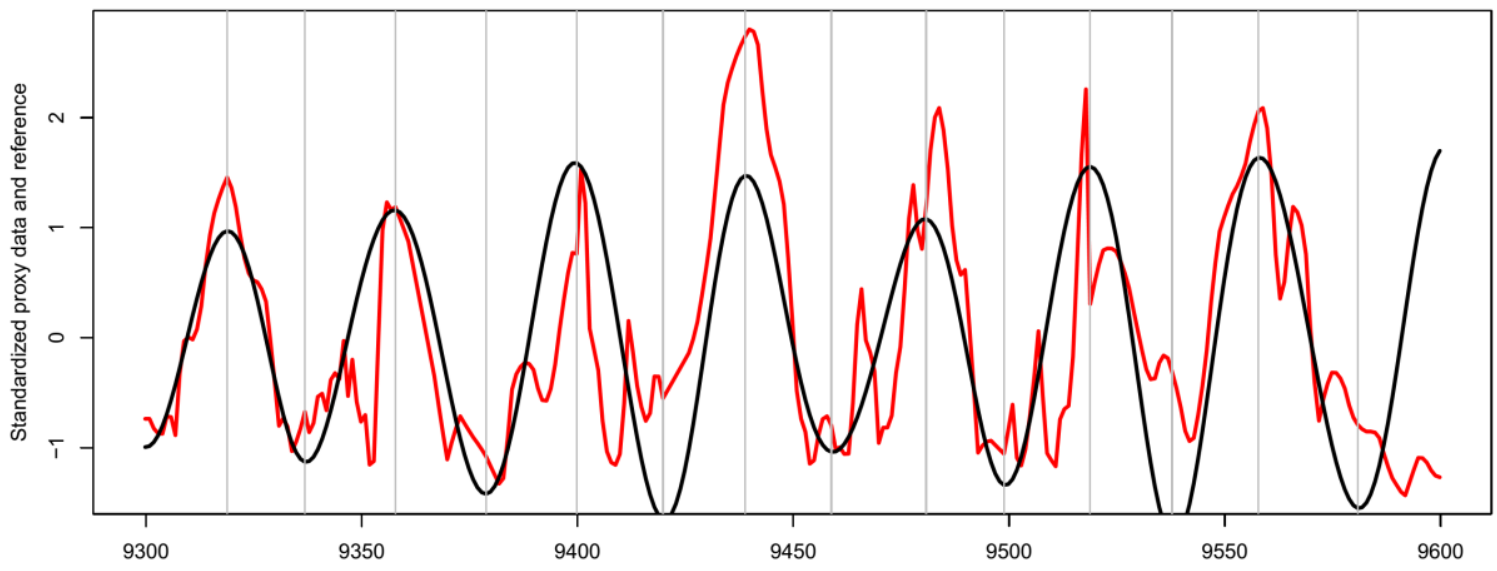

Data on adjusted (red) and original (blue) time scale, optimal target (gray)

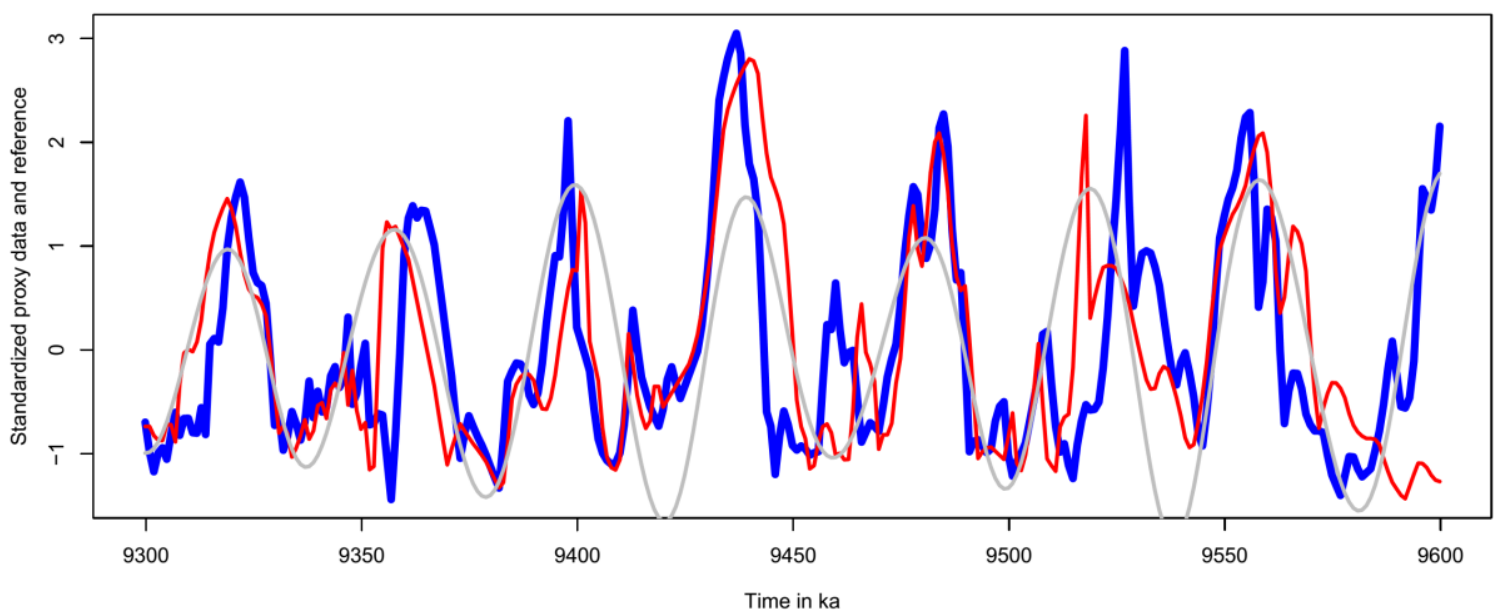

Figure 4: Older part of figure 2 showing precession-obliquity interference, an obliquity target approximates data best. Grey scale colour data form Monte dei Corvi (Zeeden et al., 2014) on the original age scale (top), the adjusted age scale (using an obliquity filter comprising both precession and obliquity; middle panel), as well as a comparison of data on original and adjusted time scales (bottom panel) including the target fitting data best (grey). Vertical lines represent tie points between filtered data and the best-fitting correlation target. (for printing: black and white) 

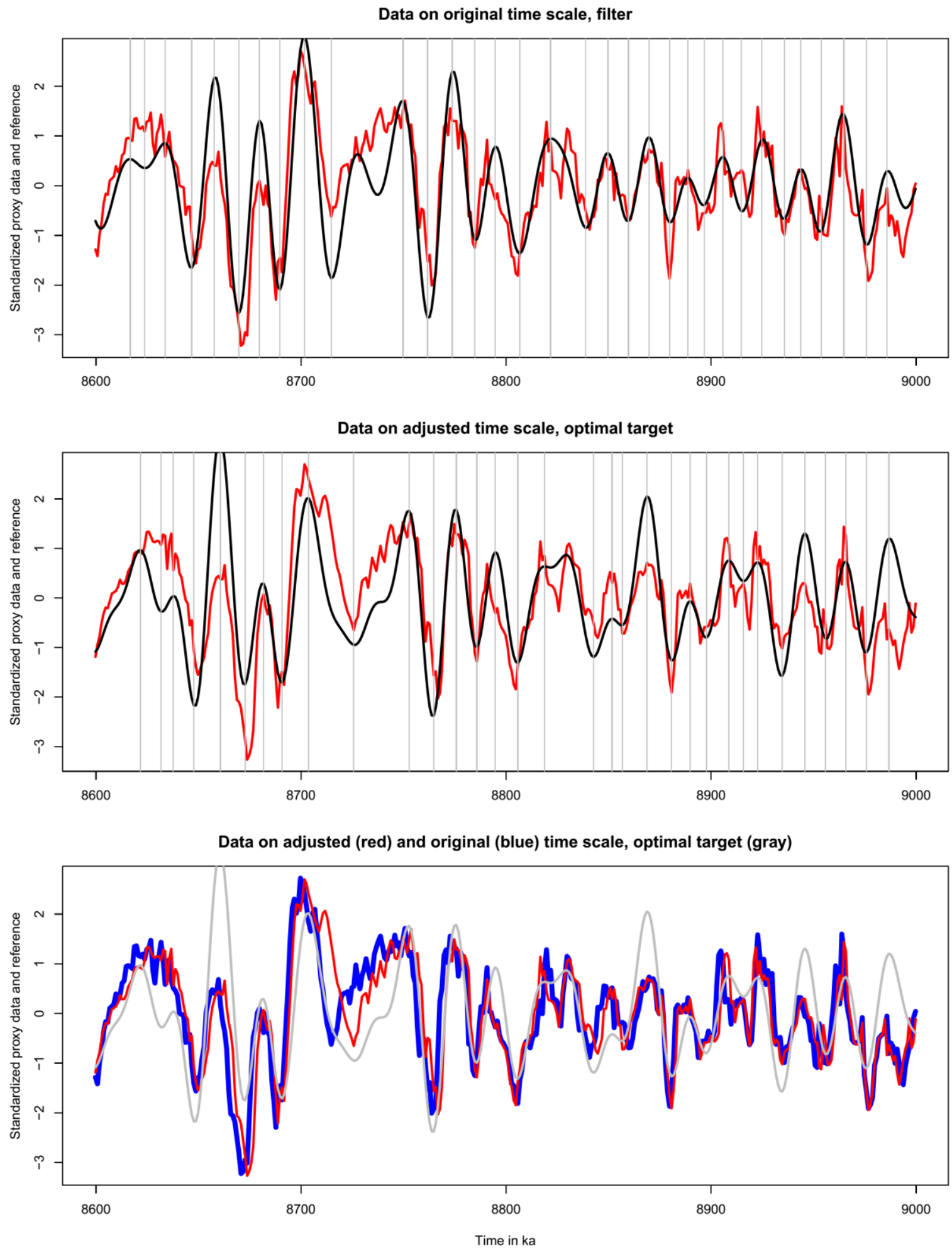

Figure 5: Grey scale colour data form the equatorial Atlantic Ceara Rise (Zeeden et al., 2013) on the original age scale (top), the adjusted age scale (using a filter comprising both precession and obliquity; middle panel), as well as a comparison of data on original and adjusted time scales (bottom panel) including the target fitting data best (grey). Vertical lines 
represent tie points between filtered data and the best-fitting correlation target. (for printing: black and white)

477 Table 1: Experiments and their respective results for testing precession filter properties. $p$ 478 denotes precession, $t$ tilt/obliquity and e eccentricity. Results from testing filter properties are displayed in columns 2 to 4 . For most results widening filters above a certain level gives similarly good correlation. Narrowing these results and avoiding similar correlation coefficients as from wider filters seems useful in real cases. Therefore, the narrowest filters with high correlation are given in columns 5 to 7 . Filter boundaries (upper- and lower frequency range boundaries) are given in 1e-3 [1/kyr].

\begin{tabular}{|c|c|c|c|c|c|c|}
\hline \multirow[b]{2}{*}{ tested data } & \multicolumn{3}{|c|}{ as by experiments } & \multicolumn{3}{|c|}{ adjusting results to useful values } \\
\hline & $\begin{array}{l}\text { lower } \\
\text { frequency }\end{array}$ & $\begin{array}{l}\text { upper } \\
\text { frequency }\end{array}$ & $\begin{array}{l}\text { roll-off } \\
\text { rate }\end{array}$ & $\begin{array}{l}\text { lower } \\
\text { frequency }\end{array}$ & $\begin{array}{l}\text { upper } \\
\text { frequency }\end{array}$ & $\begin{array}{l}\text { roll-off } \\
\text { rate }\end{array}$ \\
\hline$-p+0.5 t$ & 0.036 & 0.080 & 0.027 & $\quad 0.041$ & 0.054 & 27 \\
\hline$p+0.5 t$ & 0.045 & 0.050 & 0.040 & 0.041 & 0.054 & 27 \\
\hline$-p+0.5 t+0.5 * A R$ noise & 0.039 & 0.055 & 0.022 & 0.041 & 0.054 & 21 \\
\hline$-p+0.5 t+$ equal $A R$ noise & 0.041 & 0.054 & 0.031 & 0.041 & 0.054 & 31 \\
\hline$-p+0.5 t+2 * A R$ noise & 0.041 & 0.054 & 0.031 & 0.041 & 0.054 & 31 \\
\hline$p-t+0.5^{*} A R$ noise & 0.047 & 0.051 & 0.042 & 0.041 & 0.054 & 31 \\
\hline$p-t+$ equal AR noise & 0.047 & 0.051 & 0.042 & 0.041 & 0.054 & 31 \\
\hline$p-t+2 * A R$ noise & 0.047 & 0.051 & 0.042 & 0.041 & 0.054 & 31 \\
\hline$p+0.5 t+0.5 * A R$ noise; time domain distorted by gamma distribution & 0.036 & 0.051 & 0.029 & 0.050 & 0.054 & 27 \\
\hline$p+0.5 t+$ equal AR noise; time domain distorted by gamma distribution & 0.036 & 0.051 & 0.029 & 0.050 & 0.054 & 27 \\
\hline$p+0.5 t+2 * A R$ noise; time domain distorted by gamma distribution & 0.036 & 0.051 & 0.029 & 0.050 & 0.054 & 27 \\
\hline$p+0.5 t+0.5 * A R$ noise; time domain distorted by gamma distribution; clip data at 0 & 0.041 & 0.054 & 0.057 & 0.041 & 0.054 & 27 \\
\hline$p+0.5 t+$ equal AR noise; time domain distorted by gamma distribution; clip data at 1 & 0.041 & 0.054 & 0.063 & 0.041 & 0.054 & 27 \\
\hline$p+0.5 t+2 * A R$ noise; time domain distorted by gamma distribution; clip data at 0 & 0.041 & 0.054 & 0.063 & 0.041 & 0.054 & 26 \\
\hline mean result & 0.041 & 0.054 & 0.039 & 0.043 & 0.054 & 28 \\
\hline
\end{tabular}


486 Table 2: Evolution of suggested filter boundaries through Geological past, using the 487 evolution of astronomical frequencies as in (Laskar et al., 2004).

$\begin{array}{ccccc}\text { time in Ma } & \begin{array}{c}\text { precession low } \\ \text { filter boundary }\end{array} & \begin{array}{c}\text { precession high } \\ \text { filter boundary }\end{array} & \begin{array}{c}\text { obliquity low } \\ \text { filter boundary }\end{array} & \begin{array}{c}\text { obliquity high } \\ \text { filter boundary }\end{array} \\ 0 & 0.043 & 0.054 & 0.022 & 0.029 \\ 50 & 0.044 & 0.055 & 0.023 & 0.030 \\ 100 & 0.045 & 0.056 & 0.024 & 0.031 \\ 150 & 0.046 & 0.057 & 0.025 & 0.033 \\ 200 & 0.048 & 0.059 & 0.027 & 0.034 \\ 250 & 0.049 & 0.060 & 0.028 & 0.035 \\ 300 & 0.051 & 0.062 & 0.030 & 0.037 \\ 350 & 0.052 & 0.063 & 0.031 & 0.038 \\ 400 & 0.054 & 0.065 & 0.033 & 0.040 \\ 450 & 0.056 & 0.067 & 0.035 & 0.042 \\ 500 & 0.057 & 0.068 & 0.036 & 0.044 \\ 550 & 0.059 & 0.070 & 0.038 & 0.045 \\ 600 & 0.061 & 0.072 & 0.040 & 0.047 \\ 650 & 0.063 & 0.074 & 0.042 & 0.050 \\ 700 & 0.065 & 0.077 & 0.044 & 0.052 \\ 750 & 0.068 & 0.079 & 0.047 & 0.054 \\ 800 & 0.070 & 0.081 & 0.049 & 0.056 \\ 850 & 0.072 & 0.083 & 0.051 & 0.059 \\ 900 & 0.075 & 0.086 & 0.054 & 0.061 \\ 950 & 0.078 & 0.089 & 0.057 & 0.064 \\ 1000 & 0.080 & 0.091 & 0.059 & 0.066\end{array}$


Abels, H.A., Aziz, H.A., Ventra, D., Hilgen, F.J., 2009. Orbital Climate Forcing in Mudflat to Marginal Lacustrine Deposits in the Miocene Teruel Basin (Northeast Spain). J. Sediment. Res. 79, 831-847. https://doi.org/10.2110/jsr.2009.081

Berger, A., Loutre, M.F., Laskar, J., 1992. Stability of the Astronomical Frequencies Over the Earth's History for Paleoclimate Studies. Science 255, 560-566. https://doi.org/10.1126/science.255.5044.560

Boulila, S., Charbonnier, G., Galbrun, B., Gardin, S., 2015. Climatic precession is the main driver of Early Cretaceous sedimentation in the Vocontian Basin (France): Evidence from the Valanginian Orpierre succession. Sediment. Geol. 324, 1-11. https://doi.org/10.1016/j.sedgeo.2015.04.014

Boulila, S., Galbrun, B., Huret, E., Hinnov, L.A., Rouget, I., Gardin, S., Bartolini, A., 2014. Astronomical calibration of the Toarcian Stage: Implications for sequence stratigraphy and duration of the early Toarcian OAE. Earth Planet. Sci. Lett. 386, 98-111. https://doi.org/10.1016/j.epsl.2013.10.047

Boulila, S., Galbrun, B., Laskar, J., Pälike, H., 2012. A 9myr cycle in Cenozoic $\delta 13 \mathrm{C}$ record and long-term orbital eccentricity modulation: Is there a link? Earth Planet. Sci. Lett. 317, 273281.

Curry, W.B., Shackleton, N.J., Richter, C., others, 1995. Leg 154. Synth. Proc. ODP Initial Rep. 154, 421-442. https://doi.org/doi:10.2973/odp.proc.ir.154.109.1995

Da Silva, A.C., Hladil, J., Chadimová, L., Slavík, L., Hilgen, F.J., Bábek, O., Dekkers, M.J., 2016. Refining the Early Devonian time scale using Milankovitch cyclicity in Lochkovian-Pragian sediments (Prague Synform, Czech Republic). Earth Planet. Sci. Lett. 455, 125-139. https://doi.org/10.1016/j.epsl.2016.09.009

Ding, Z.L., Derbyshire, E., Yang, S.L., Yu, Z.W., Xiong, S.F., Liu, T.S., 2002. Stacked 2.6-Ma grain size record from the Chinese loess based on five sections and correlation with the deep-sea $\delta 180$ record. Paleoceanography 17, 5-1. https://doi.org/10.1029/2001PA000725

Dobson, D.M., Dickens, G.R., Rea, D.K., 2001. Terrigenous sediment on Ceara Rise: a Cenozoic record of South American orogeny and erosion. Palaeogeogr. Palaeoclimatol. Palaeoecol. 165, 215-229. https://doi.org/10.1016/S0031-0182(00)00161-9

Edwards, J., Lallier, F., Caumon, G., Carpentier, C., 2018. Uncertainty management in stratigraphic well correlation and stratigraphic architectures: A training-based method. Comput. Geosci. 111, 1-17. https://doi.org/10.1016/j.cageo.2017.10.008

Harris, S.E., Mix, A.C., King, T., 1997. Biogenic and terrigenous sedimetations at Ceara rise, western tropical Altantic, supports Pliocene-Pleistocene deep-water linkage between hemispheres 154, 331-345. https://doi.org/doi:10.2973/odp.proc.sr.154.114.1997

Hilgen, F., Zeeden, C., Lourens, L., 2014. Comment on Colleoni et al.(2012): Integrated stratigraphy and pitfalls of automated tuning. Earth Planet. Sci. Lett. 387, 22-24. https://doi.org/10.1016/j.epsl.2013.11.013

Hilgen, F.J., Abdul Aziz, H., Krijgsman, W., Raffi, I., Turco, E., 2003. Integrated stratigraphy and astronomical tuning of the Serravallian and lower Tortonian at Monte dei Corvi (Middle-Upper Miocene, northern Italy). Palaeogeogr. Palaeoclimatol. Palaeoecol. 199, 229-264. https://doi.org/10.1016/S0031-0182(03)00505-4

Hilgen, F.J., Hinnov, L.A., Aziz, H.A., Abels, H.A., Batenburg, S., Bosmans, J.H.C., Boer, B. de, Hüsing, S.K., Kuiper, K.F., Lourens, L.J., Rivera, T., Tuenter, E., Wal, R.S.W.V. de, Wotzlaw, J.-F., Zeeden, C., 2015. Stratigraphic continuity and fragmentary sedimentation: the success of cyclostratigraphy as part of integrated stratigraphy. Geol. Soc. Lond. Spec. Publ. 404, 157197. https://doi.org/10.1144/SP404.12

Hinnov, L.A., 2000. New Perspectives on Orbitally Forced Stratigraphy. Annu. Rev. Earth Planet. Sci. 28, 419-475. https://doi.org/10.1146/annurev.earth.28.1.419

Hinnov, L.A., Hilgen, F.J., 2012. Chapter 4 - Cyclostratigraphy and Astrochronology, in: Gradstein, F.M., Ogg, J.G., Schmitz, M.D., Ogg, G.M. (Eds.), The Geologic Time Scale. Elsevier, Boston, pp. 63-83.

Hüsing, S.K., Cascella, A., Hilgen, F.J., Krijgsman, W., Kuiper, K.F., Turco, E., Wilson, D., 2010. Astrochronology of the Mediterranean Langhian between 15.29 and 14.17 Ma. Earth Planet. Sci. Lett. 290, 254-269. https://doi.org/10.1016/j.epsl.2009.12.002

Hüsing, S.K., Hilgen, F.J., Abdul Aziz, H., Krijgsman, W., 2007. Completing the Neogene geological time scale between 8.5 and 12.5 Ma. Earth Planet. Sci. Lett. 253, 340-358. https://doi.org/10.1016/j.epsl.2006.10.036 
Hüsing, S.K., Kuiper, K.F., Link, W., Hilgen, F.J., Krijgsman, W., 2009. The upper Tortonian-lower Messinian at Monte dei Corvi (Northern Apennines, Italy): Completing a Mediterranean reference section for the Tortonian Stage. Earth Planet. Sci. Lett. 282, 140-157. https://doi.org/10.1016/j.epsl.2009.03.010

Huybers, P., Aharonson, O., 2010. Orbital tuning, eccentricity, and the frequency modulation of climatic precession. Paleoceanography 25. https://doi.org/10.1029/2010PA001952

Kaboth, S., Bahr, A., Reichart, G.-J., Jacobs, B., Lourens, L.J., 2016. New insights into upper MOW variability over the last 150kyr from IODP 339 Site U1386 in the Gulf of Cadiz. Mar. Geol., 377, 136-145. https://doi.org/10.1016/j.margeo.2015.08.014

Kodama, K.P., 2015. Rock magnetic cyclostratigraphy. Wiley Blackwell, Oxfordshire, England.

Kotov, S., De Vleeschouwer, D., Martinez, M., Pälike, H., 2016. A signal matching algorithm based on Dynamic Time Warping. Presented at the 35th IGC, Cape Town.

Kuiper, K.F., Deino, A., Hilgen, F.J., Krijgsman, W., Renne, P.R., Wijbrans, J.R., 2008. Synchronizing Rock Clocks of Earth History. Science 320, 500-504. https://doi.org/10.1126/science.1154339

Lang, N., Wolff, E.W., 2011. Interglacial and glacial variability from the last $800 \mathrm{ka}$ in marine, ice and terrestrial archives. Clim. Past 7, 361-380. https://doi.org/10.5194/cp-7-361-2011

Laskar, J., Robutel, P., Joutel, F., Gastineau, M., Correia, A.C.M., Levrard, B., 2004. A long-term numerical solution for the insolation quantities of the Earth. Astron. Astrophys. 428, 261-285. https://doi.org/10.1051/0004-6361:20041335

Laurin, J., Meyers, S.R., Galeotti, S., Lanci, L., 2016. Frequency modulation reveals the phasing of orbital eccentricity during Cretaceous Oceanic Anoxic Event II and the Eocene hyperthermals. Earth Planet. Sci. Lett. 442, 143-156. https://doi.org/10.1016/j.epsl.2016.02.047

Li, M., Hinnov, L.A., Huang, C., Ogg, J.G., 2018. Sedimentary noise and sea levels linked to landocean water exchange and obliquity forcing. Nat. Commun. 9, 1004. https://doi.org/10.1038/s41467-018-03454-y

Liebrand, D., Lourens, L.J., Hodell, D.A., de Boer, B., van de Wal, R.S.W., Pälike, H., 2011. Antarctic ice sheet and oceanographic response to eccentricity forcing during the early Miocene. Clim Past 7, 869-880. https://doi.org/10.5194/cp-7-869-2011

Lin, L., Khider, D., Lisiecki, L.E., Lawrence, C.E., 2014. Probabilistic sequence alignment of stratigraphic records. Paleoceanography 29, 976-989.

Lisiecki, L.E., Lisiecki, P.A., 2002. Application of dynamic programming to the correlation of paleoclimate records. Paleoceanography 17, 1049. https://doi.org/10.1029/2001PA000733

Lisiecki, L.E., Raymo, M.E., 2005. A Pliocene-Pleistocene stack of 57 globally distributed benthic $\delta 180$ records. Paleoceanography 20, PA1003. https://doi.org/10.1029/2004PA001071

Lourens, L.J., Antonarakou, A., Hilgen, F.J., Van Hoof, A. a. M., Vergnaud-Grazzini, C., Zachariasse, W.J., 1996. Evaluation of the Plio-Pleistocene astronomical timescale. Paleoceanography 11, 391-413. https://doi.org/10.1029/96PA01125

Lourens, L.J., Becker, J., Bintanja, R., Hilgen, F.J., Tuenter, E., van de Wal, R.S.W., Ziegler, M., 2010. Linear and non-linear response of late Neogene glacial cycles to obliquity forcing and implications for the Milankovitch theory. Quat. Sci. Rev. 29, 352-365. https://doi.org/10.1016/j.quascirev.2009.10.018

Lourens, L.J., Wehausen, R., Brumsack, H.J., 2001. Geological constraints on tidal dissipation and dynamical ellipticity of the Earth over the past three million years. Nature 409, 1029-1033. https://doi.org/10.1038/35059062

Marković, S.B., Stevens, T., Kukla, G.J., Hambach, U., Fitzsimmons, K.E., Gibbard, P., Buggle, B., Zech, M., Guo, Z., Hao, Q., others, 2015. Danube loess stratigraphy-Towards a panEuropean loess stratigraphic model. Earth-Sci. Rev. 148, 228-258.

Martinez, M., Dera, G., 2015. Orbital pacing of carbon fluxes by a 9-My eccentricity cycle during the Mesozoic. Proc. Natl. Acad. Sci. 112, 12604-12609.

Martinez, M., Kotov, S., De Vleeschouwer, D., Pas, D., Pälike, H., 2016. Testing the impact of stratigraphic uncertainty on spectral analyses of sedimentary series. Clim Past 12, 17651783. https://doi.org/10.5194/cp-12-1765-2016

Martinez, M., Krencker, F.-N., Mattioli, E., Bodin, S., 2017. Orbital chronology of the PliensbachianToarcian transition from the Central High Atlas Basin (Morocco). Newsl. Stratigr. 50, 47-69.

Meyers, S.R., 2015. The evaluation of eccentricity-related amplitude modulation and bundling in paleoclimate data: An inverse approach for astrochronologic testing and time scale optimization. Paleoceanography 30, 1625-1640.

Meyers, S.R., 2014. astrochron: An R Package for Astrochronology Version 0.6.5. 
Meyers, S.R., Hinnov, L.A., 2010. Northern Hemisphere glaciation and the evolution of PlioPleistocene climate noise. Paleoceanography 25. https://doi.org/10.1029/2009PA001834

Necula, C., Panaiotu, C., 2008. Application of dynamic programming to the dating of a loess-paleosol sequence. Romanian Rep. Phys. 60, 157-171.

Olea, R.A., 1994. Expert systems for automated correlation and interpretation of wireline logs. Math. Geol. 26, 879-897. https://doi.org/10.1007/BF02083420

Pälike, H., 2002. Extending the geological calibration of the geological time scale. University of Cambridge.

Pälike, H., Frazier, J., Zachos, J.C., 2006a. Extended orbitally forced palaeoclimatic records from the equatorial Atlantic Ceara Rise. Quat. Sci. Rev. 25, 3138-3149. https://doi.org/10.1016/j.quascirev.2006.02.011

Pälike, H., Norris, R.D., Herrle, J.O., Wilson, P.A., Coxall, H.K., Lear, C.H., Shackleton, N.J., Tripati, A.K., Wade, B.S., 2006b. The Heartbeat of the Oligocene Climate System. Science 314, 1894-1898. https://doi.org/10.1126/science.1133822

R Core Team, 2017. R: A Language and Environment for Statistical Computing.

Rutherford, S., D'Hondt, S., 2000. Early onset and tropical forcing of 100,000-year Pleistocene glacial cycles. Nature 408, 72-75. https://doi.org/10.1038/35040533

Shackleton, N.J., Crowhurst, S., 1997. Sediment fluxes based on an orbitally tuned time scale $5 \mathrm{Ma}$ to $14 \mathrm{Ma}$, Site 926. Proc ODP Sci Results 154, 69-82. https://doi.org/10.2973/odp.proc.sr.154.102.1997

Shackleton, N.J., Crowhurst, S.J., Weedon, G.P., Laskar, J., 1999. Astronomical calibration of Oligocene--Miocene time. Philos. Trans. R. Soc. Lond. Ser. Math. Phys. Eng. Sci. 357, 19071929. https://doi.org/10.1098/rsta.1999.0407

Shackleton, N.J., Hagelberg, T.K., Crowhurst, S.J., 1995. Evaluating the success of astronomical tuning: Pitfalls of using coherence as a criterion for assessing pre-Pleistocene timescales. Paleoceanography 10, 693-697. https://doi.org/10.1029/95PA01454

Taner, M.T., 1992. in: Attributes revisted (Technical Report, Rock Solid Images, Inc), url: http://www.rocksolidimages.com/attributes-revisited/\#_Toc328470897.

Thompson, W.G., Goldstein, S.L., 2006. A radiometric calibration of the SPECMAP timescale. Quat. Sci. Rev., Critical Quaternary Stratigraphy 25, 3207-3215. https://doi.org/10.1016/j.quascirev.2006.02.007

Valero, L., Cabrera, L., Sáez, A., Garcés, M., 2016. Long-period astronomically-forced terrestrial carbon sinks. Earth Planet. Sci. Lett. 444, 131-138. https://doi.org/10.1016/j.epsl.2016.03.038

Valero, L., Garcés, M., Cabrera, L., Costa, E., Sáez, A., 2014. 20 Myr of eccentricity paced lacustrine cycles in the Cenozoic Ebro Basin. Earth Planet. Sci. Lett. 408, 183-193. https://doi.org/10.1016/j.epsl.2014.10.007

Wilkens, R., Westerhold, T., Drury, A.J., Lyle, M., Gorgas, T., Tian, J., 2017. Revisiting the Ceara Rise, equatorial Atlantic Ocean: isotope stratigraphy of ODP Leg 154. Clim. Past 2017, 1-22. https://doi.org/10.5194/cp-2016-140

Wotzlaw, J.-F., Hüsing, S.K., Hilgen, F.J., Schaltegger, U., 2014. High-precision zircon U-Pb geochronology of astronomically dated volcanic ash beds from the Mediterranean Miocene. Earth Planet. Sci. Lett. 407, 19-34. https://doi.org/10.1016/j.epsl.2014.09.025

Wu, H., Zhang, S., Hinnov, L.A., Jiang, G., Feng, Q., Li, H., Yang, T., 2013. Time-calibrated Milankovitch cycles for the late Permian. Nat. Commun. 4. https://doi.org/10.1038/ncomms3452

Zeeden, C., Hilgen, F., Westerhold, T., Lourens, L., Röhl, U., Bickert, T., 2013. Revised Miocene splice, astronomical tuning and calcareous plankton biochronology of ODP Site 926 between 5 and 14.4 Ma. Palaeogeogr. Palaeoclimatol. Palaeoecol. 369, 430-451. https://doi.org/10.1016/j.palaeo.2012.11.009

Zeeden, C., Hilgen, F.J., Hüsing, S.K., Lourens, L.L., 2014. The Miocene astronomical time scale 9$12 \mathrm{Ma}$ : New constraints on tidal dissipation and their implications for paleoclimatic investigations. Paleoceanography 29, 2014PA002615. https://doi.org/10.1002/2014PA002615

Zeeden, C., Meyers, S.R., Lourens, L.J., Hilgen, F.J., 2015. Testing astronomically tuned age models. Paleoceanography 30, 2014PA002762. https://doi.org/10.1002/2014PA002762 